\title{
Correction to: Development of Cold Spray Coatings for Accident-Tolerant Fuel Cladding in Light Water Reactors
}

\author{
BENJAMIN MAIER,${ }^{1}$ HWASUNG YEOM,${ }^{1}$ GREG JOHNSON, ${ }^{1}$ \\ TYLER DABNEY, ${ }^{1}$ JORIE WALTERS, ${ }^{1}$ JAVIER ROMERO ${ }^{2}$ \\ HEMANT SHAH ${ }^{2}$ PENG XU ${ }^{2}$ and KUMAR SRIDHARAN ${ }^{1,3}$ \\ 1.-Department of Engineering Physics, University of Wisconsin-Madison, Madison, WI 53706, \\ USA. 2.-Westinghouse Electric Company, Hopkins, SC 29061, USA. 3.-e-mail: \\ kumar@engr.wisc.edu
}

\section{Correction to: \\ JOM}

https://doi.org/10.1007/s11837-017-2643-9

This article was updated. The title was corrected to read Light Water Reactors. 